\title{
Introduction: Emergency Preparedness
}

\author{
by Sir David Veness
}

${ }^{6} \mathrm{H}$ omeland Security in the UK" edited by Paul Wilkinson and published in 2007 remains a magisterial review of the terrorist threat, preparedness and response. The book is based upon a study on "The preparedness of the UK for future terrorist attack" funded by the Economic and Social Research Council and conducted between 2002 and 2006.

The Memorial Service for Paul Wilkinson was held on 16 February 2012 and was preceded by an event entitled "Assessing the Emergency Response to Terrorism". This conference had been instigated by Paul before his sad death.

In anticipation of chairing a session at the seminar, I re-read Paul's book. This prompted two thoughts. Firstly, the great debt owed to Paul by a generation of counter-terrorist practitioners for his unfailing inspiration, support and his encouragement to think more deeply and widely about the subject. In doing so, he made a vital contribution to public protection, safety and security.

Secondly, to ponder how timely it would be to conduct an exercise similar to that undertaken by Paul and his distinguished colleagues between 2002 and 2006. The key issues of concern remain pressing and relevant.

This special edition of the Journal of Terrorism Research includes an account of the presentations made at this impressive conference. The range of subject matter is striking. Whilst the programme was categorized into three segments - assessing the past, current and future threats - the presenters addressed a remarkable span of topics.

This breadth underlined the key feature of emergency preparedness. To provide public protection, it must function at global, regional, national and local levels. It must be multi-disciplinary

encompassing diverse skills and specialisms. Furthermore, it is inherently a multi-agency challenge. Each of the speakers illustrated these topics from different angles.

My personal observation on this breadth and complexity was to note what organizational challenges this presents. Cross sector effort even at the level of just one national government has not produced a record of consistent success. When this challenge is repeated at multi-national tiers, the problems are even greater. There is no doubt that multi-disciplinary and multi-agency co-operation also requires systematic investment and constant maintenance.

The second challenge on which I pondered was that of terrorist innovation. Emergency preparedness is inevitably most effective in dealing with past threats. The tragedy of $9 / 11$ itself was a remarkable demonstration of terrorist innovation combining the expected threat of aircraft hijacking with the dimension of ground attack. This was sufficient to defeat the defences of the world's greatest power. In the years since 9/11 innovation has continued, noticeably with the spread of suicide bombing and the intention to cause higher casualties. Fedayeen-style attacks have been conducted notably in Mumbai. There is no doubt that terrorists will use even more deadly forms of attack if they can make them work. 


\section{Journal of Terrorism Research}

This means that emergency preparedness is especially vulnerable because it must not only address previous attacks but anticipate novelty. Herein lies a great susceptibility to terrorist developments in tactics, techniques and procedures in addition to attack methods and target choices.

The 9/11 Commission Report (Chapter 11) includes a description of a "failure of imagination" in counter-terrorism. Applying this statement to emergency preparedness it is difficult to conclude that the lessons have been fully learnt.

These twin thoughts of the complexity of emergency preparedness and its vulnerability to innovation were at the front of my mind as I listened to each of the excellent speakers. They provided insights which underlined these notions, but gave them much greater depth and balance. My conclusion was that this conference should be part of a process of continual assessment and development and I am certain that Paul would wish to see practical outcomes from this event, especially linking academic research with front-line response.

Sir David Omand in the opening presentation lucidly placed emergency preparedness for terrorist attacks in the much broader context of the widest range of major threats and hazards. He illustrated the different paths of "sudden impact" and "rising tide" events. Reflecting on the main lesson of the past decade, Sir David emphasized the "importance of affording time and effort to be best able to judge the underlying nature and potential gravity of a terrorist threat". The significance of this point was emphasized by the fact that it was clearly echoed in the contributions from Dr. Gilbert Ramsay and Dr. Anthony Richards who defined the threat and explored ideology, tactics and targeting.

Dr. Gilbert Ramsay's paper in this collection progresses an important aspect of the theme he presented at the conference. His general theme was the suggestion that the threat of international terrorism involves two Jihads: one Global and one more localized including Western venues. Whilst these may overlap, he identifies different operational and targeting agendas. In this paper he develops the debate about plots and attacks in the West. There are strands within this argument which are of clear relevance to emergency preparedness especially the rationale for diverse attack methods. From my perspective it would be useful to pursue further analysis on these aspects. One specific example would be to further evaluate the impact and consequences of different types of improvised explosive devices (IEDs) including remote controlled bombs in a wider range of target locations.

Dr. Anthony Richards cogently explains why counter-terrorism needs to be primarily engaged with combating violent actions. As emergency preparedness is immediately concerned with the impact upon victims of terrorism, the wisdom of his thesis will be readily understood by practitioners. This is especially pertinent in times of challenging resource limitations. He also explores flaws in the tendency to link terrorism with human vulnerability. This again echoes with counter-terrorists who would support the perspective that terrorism is calculated violence and that counter measures should address this reality.

The interplay between actions to achieve emergency preparedness at global, regional, national and local levels emerged clearly from the day's proceedings. Strikingly, Professor Malcolm Dando made a compelling case for greater political and academic effort to enhance the effectiveness of the Biological and Toxin Weapons Convention. Most soberingly, he explained the lack of awareness amongst life scientists on aspects of bio-security. His conclusion was that these deficiencies will mean that potential malevolent use of the life sciences by terrorists or others remains a persistent danger.

It struck me that this was a clear example of the linkage between the global and the local. Inadequate effort at the global level means that local emergency preparedness is made more 


\section{Journal of Terrorism Research}

difficult. This difficulty is made worse by the likely local perceptions of the threat, competition from other risks and the expense of response mechanisms.

The multi-disciplinary dimensions of emergency preparedness were vividly described by both Simon Lewis and Montine Walters especially as regards the essential combination of talents drawn from security, medicine and victim identification. Montine Walters emphasized the vital contribution of first aid before professional first responders arrive at the scene of an incident.

Simon Lewis also set out the history and current practice of the multi-agency effort in London with particular emphasis on the lessons following the attacks of 7/7/2005. Montine Walters interestingly implied that we should also consider the crowd at an incident as an agency to deliver immediate assistance. This is an example of learning from one jurisdiction - Israel - which could be applied to other countries.

It was interesting that these themes of geographically linked endeavours, multi-disciplinary and multi-agency aspects resonated with the large number of emergency service practitioners who were present at the conference. They shared the view that untiring effort was needed to fit together the components of the overall effort. They also expressed concern that our preparations looked backward not forward.

The operators also emphasized that some problems with emergency response such as communication, inter-operability and comprehensive care of those impacted by an incident are persistent despite commendable progress on each theme. I know they will find these collective papers a valuable contribution to continuing development.

In conclusion, I commend this conference collection as an excellent source of important information and a spur to further work. A great debt is owed to each of the speakers, to the conference organizers and, above all, to Paul Wilkinson who inspired this gathering. 